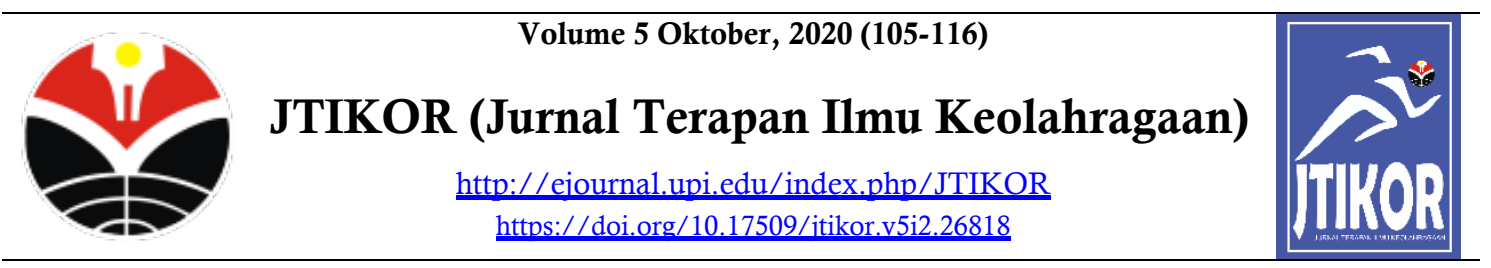

\title{
Pengaruh Senam Aerobik dan Motivasi Latihan Terhadap Penurunan Persentase Lemak Tubuh
}

\author{
Indah Putri Nuarye, Muhamad Sazeli Rifki ${ }^{\bowtie}$, Wilda Welis, Syamsuar Abbas \\ Program Studi Pendidikan Olahraga, Fakultas Ilmu Keolahragaan, Universitas Negeri Padang, \\ Sumatera Barat, Indonesia
}

\section{Info Artikel \\ Kata Kunci: \\ Senam aerobic low impact, mixed impact, motivasi latihan, persentase lemak tubuh. \\ Keywords: \\ Low impact aerobic exercise, mixed impact, exercise motivation, body fat percentage.}

$\triangle$ Jalan Prof. Dr. Hamka, Air Tawar Padang, Sumatera Barat E-mail: msr rifki@fik.unp.ac.id

\begin{abstract}
Abstrak
Tujuan penelitian ini penelitian ini adalah untuk mengetahui pengaruh senam aerobik dan motivasi latihan terhadap penurunan persentase lemak tubuh member sanggar senam D'Ladies Kota Padang. Jenis penelitian ini adalah ekperimen dengan rancangan faktorial By Level 2 × 2. Penarikan sampel menggunakan teknik Purposive Sampling, sehingga sampel berjumlah 40 orang dengan kriteria umur 20-30 tahun. Instrument lemak tubuh menggunakan Body Fat Analyzer dan motivasi latihan menggunakan angket model skala Likert. Data di analisis menggunakan ANOVA 2 × 2 dan uji lanjut Tukey pada $\alpha=0,05$. Hasil pengujian hipotesis menunjukkan, (1) terdapat perbedaan pengaruh antara senam aerobik Mixed Impact dan senam aerobik Low Impact terhadap penurunan persentase lemak tubuh, (2) terdapat interaksi antara senam aerobik dengan motivasi latihan terhadap penurunan persentase lemak tubuh, (3) terdapat perbedaan pengaruh senam aerobik Mixed Impact dan senam aerobik Low Impact dilihat dari motivasi latihan tinggi, dan (4) tidak terdapat perbedaan pengaruh senam aerobik Mixed Impact dan senam aerobik Low Impact dilihat dari motivasi latihan rendah. Dapat disimpulkan, bahwa senam aerobik Mixed Impact lebih baik dibandingkan senam aerobik Low Impact dalam penurunan persentase lemak tubuh jika dilihat dari motivasi latihan tinggi. Sedangkan untuk motivasi latihan rendah dapat diberikan kedua perlakuan terhadap penurunan persentase lemak tubuh.
\end{abstract}

\begin{abstract}
This study aimed to determine the effect of aerobic exercise and motivation on decreasing body fat percentage of members of the D'Ladies Gymnastics Gymnastics Padang. This type of research is an experiment with a factorial design By Level $2 \times 2$. The sample was drawn using the purposive sampling technique so that the sample amounted to 40 people with criteria aged 20-30 years. Body fat instrument using Body Fat Analyzer and training motivation using Likert scale model questionnaire. Data were analyzed using ANOVA $2 \times 2$ and Tukey's follow-up test at $\alpha=0.05$. The results of hypothesis testing show, (1) there is a difference in the effect of Mixed Impact aerobic exercise and Low Impact aerobic exercise on decreasing body fat percentage, (2) there is an interaction between aerobic exercise and motivation on decreasing body fat percentage, (3) there is a difference in effect. Mixed Impact aerobic exercise and Low Impact aerobic exercise are seen from high training motivation, and (4) there is no difference in Mixed Impact aerobic exercise and Low Impact aerobic exercise seen from low training motivation. It can be concluded that Mixed Impact aerobic exercise is better than Low Impact aerobic exercise in reducing body fat percentage when seen from high training motivation. As for low exercise motivation, both treatments can be given to decrease the percentage of body fat.
\end{abstract}

Copyright $(C) 2020$, Authors 


\section{PENDAHULUAN}

Kebutuhan akan makanan dan minuman pada saat sekarang ini sudah banyak berbagai macam komposisi zat gizi yang lengkap, baik cepat saji (Fast Food) maupun siap saji (Junk Food). Makanan dan minuman cepat saji membuat masyarakat praktis mengkonsumsinya. Contoh lain ketika kita ingin makan, tetapi tidak banyak waktu untuk memasak sendiri ataupun membeli, seseorang hanya perlu memakai jasa "Delivery Order" makanan siap tersedia tanpa harus bersusah payah mendapatkannya, banyak masyarakat yang tidak menyadari efek negatif dari pekermbangan teknologi yang diiringi ketersediaan makanan dan minuman cepat saji, salah satunya memungkinkan masyarakat kurang melakukan aktivitas gerak, dan pola konsumsi makanan yang meningkat dan tidak terkendali berpengaruh pada tingkat kesehatan dan kebugaran. Seperti yang dikemukakan oleh (Almatsier, 2004) "pedoman pola makan menu seimbang yang dikembangkan sejak tahun 1950 dan telah mengakar di kalangan masyarakat luas adalah Pedoman Menu 4 Sehat 5 Sempurna. Pedoman ini pada tahun 1995 telah dikemnbangkan menjadi Pedoman Umum Gizi Seimbang yang memuat $13 \%$ dasar gizi seimbang".

Akibat dari kesibukan bekerja dan peralatan yang serba canggih, kebanyakan masyarakat sekarang kurang memiliki waku luang untuk menyajikan makanannya sendiri, kebanyakan masyarakat memiliki kebiasaan mengkonsumsi makanan cepat saji, tanpa memikirkan kandungan zat gizi pada makanan sehat untuk tubuh. Pada umumnya masyarakat beranggapan, makanan cepat saji dan siap saji selain praktis dalam mengkonsumsinya, juga telah mengandung zat gizi makanan seimbang yang diperlukan oleh tubuh, serta dapat memenuhi rasa lapar.(Kurniadi, 2006) menyatakan "Fast Food dan Soft Drink tak berguna bagi tubuh, bahkan kandungan lemaknya yang tinggi mengakibatkan kegemukan dan membahayakan kesehatan". "Jika seseorang memiliki kelebihan energi yang berasal dari lemak kelebihannya akan disimpan di bawah kulit dalam bentuk lemak tubuh.
Timbunan lemak tubuh ini ternyata memiliki fungsi khusus sebagai cadangan energi yang sewaktu-waktu dapat digunakan dan bantalan organ-organ tubuh. Namun, jika lemak tersebut tidak terpakai dalam jangka waktu yang lama, timbunan lemaknya akan semakin banyak sehingga menyebabkan seseorang kelebihan berat badan dan menjadi gemuk(Sumanto, 2009)".

Obesitas atau kegemukan adalah kelebihan berat badan dimana terjadi penumpukan lemak di atas ambang normal. Penumpukan kadar lemak diakibatkan asupan makanan yang masuk tidak seimbang dengan energi yang terpakai. Asupan makanan yang mengandung karbohidrat dan lemak yang tidak terpakai akan disimpan sebagai cadangan makanan di jaringan Adipose, jika tubuh memerlukan energi maka cadangan makanan yang tersimpan di jaringan Adipose akan terurai dan diproses menjadi suatu energi. "Kegemukan atau obesitas adalah suatu kondisi medis berupa kelebihan lemak tubuh yang terakumulasi sedemikian rupa sehingga menimbulkan dampak merugikan bagi kesehatan, yang kemudian menurunkan harapan hidup dan/atau meningkatkan masalah kesehatan. Seseorang dianggap menderita kegemukan (obese) bila indeks massa tubuh (IMT), yaitu ukuran yang diperoleh dari hasil pembagian berat badan dalam kilogram dengan kuadrat tinggi badan dalam meter, lebih dari $30 \mathrm{~kg} / \mathrm{m} 2$ (Asriah \& Prasetyo, 2018)".

Kegemukan juga merupakan penyakit yang kompleks karena melibatkan interaksi dari faktor resiko, antara lain kelebihan makanan, kurang gerak atau olahraga, gangguan metabolisme lemak dan genetik. Kegemukan tidak saja mengurangi daya tarik, tetapi juga menjadi masalah kesehatan baik anak-anak, remaja ataupun pada orang dewasa. (Hembing, 2001) mengemukakakan, "adanya kelebihan lemak dalam tubuh sering menjadikan seseorang penderita obesitas merasa menderita, gerakannya serba lamban dan tidak gesit sementara kehidupan modern menuntut serba cepat". (Moehji, 2017) juga mengemukana, "orang gemuk di dalam badannya terdapat 
timbunan lemak dalam jumlah yang berlebih disekitaran jantung, paru-paru, ginjal dan alatalat tubuh yang lain". Implikasinya, bahwa orang yang gemuk dalam bergerak lambat dan tidak gesit serta lebih mudah terserang penyakit. "Obesity may not only cause overweight but also other severe effects. It could lead to the emergence of a variety of degenerative diseases such as coronary heart disease, hypertension, diabetes mellitus, and rheumatism. In addition, obesity could affect the physical appearance, such as slow body movement and less attractive look (Nawawi, 2014)". Dengan kata lain, Obesitas tidak hanya menyebabkan kelebihan berat badan tetapi juga efek parah lainnya. Hal tersebut dapat memicu munculnya berbagai penyakit Degeneratif seperti penyakit jantung koroner, hipertensi, diabetes melitus, dan rematik. Selain itu, obesitas dapat mempengaruhi penampilan fisik, seperti gerakan tubuh yang lambat dan penampilan yang kurang menarik.

Mengantisipasi kegemukan tersebut, saat ini banyak masyarakat yang mengikuti klub kebugaran yang menawarkan berbagai macam program. Kegiatan berolahraga di klub kebugaran sekarang ini bukan lagi menjadi suatu kebutuhan melainkan juga menjadi suatu gaya hidup tersendiri bagi masyarakat Indonesia. Berolahraga di klub kebugaran dapat menjadi gaya hidup karena selain mendapatkan tubuh yang sehat, setiap orang juga dapat memiliki penampilan yang menarik serta di klub kebugaran menawarkan berbagai macam jenis olahraga yang dapat menurukan berat badan salah satunya adalah senam aerobik. Selain itu, kelebihan berolahraga di klub kebugaran adalah memiliki jadwal latihan yang teratur sehingga dapat dicapai hasil yang lebih efektif dan maksimal. Namun, karena di klub olahraga telah menjadi tren dan gaya hidup, maka motivasi para peserta klub olahraga yang biasa kita sebut member bermacam-macam. Ada yang memang ingin menurunkan berat badan, ada yang untuk bertemu teman-teman atau hanya ingin mengisi waktu luang. Dengan berbagai motivasi setiap member mengikuti kegiatan di klub olahraga maka akan berpengaruh pula terhadap hasil yang didapat.

Senam aerobik dipilih menjadi salah satu solusi untuk masalah kelebihan berat badan karena senam aerobik termasuk ke dalam olahraga dengan sistem energi aerobik. Sistem energi aerobik adalah suatu kegiatan fisik yang membutuhkan energi oksigen dalam melakukan aktivitas tubuh. Sistem aerobik ini selain menggunakan glukosa juga menggunakan nutrisi lain yaitu lemak dan protein. Sistem energi ini akan terpakai pada intensitas kerja rendah dan dalam waktu yang lama. "AE seems to be an effective intervention for weight loss in women, but the type of $\mathrm{AE}$ and the duration of the intervention should be considered (Hiklová \& Gába, 2019) ". Dapat disimpulkan bahwa senam, aerobik merupakan Intervensi yang efektif untuk menurunkan berat badan pada wanita, tetapi jenis senam aerobik dan durasi Intervensi harus dipertimbangkan. "manfaat senam aerobik yaitu dapat membentuk tubuh menjadi lebih proporsional, tampak awet muda, mengurangi lemak bagi yang obesitas, mencegah penyakit, meningkatkan kebugaran, membentuk otot, mengurangi ketegangan dan dapat menimbulkan kegembiraan (Dewi \& Muhammad Sazeli Rifki, 2020)". "Senam aerobik dapat berdampak pada dayatahantubuh terhadap penyakit (Purwanto, 2011)".

Namun, pada data di lapangan yang diperoleh ketika observasi di sanggar senam D'Ladies kota Padang kebanyakan yang menjadi member adalah yang bermasalah dengan berat badan. Dari 80 member yang aktif, 40 anggota mengalami obesitas. Member di sanggar senam ini berusia 20 sampai 50 tahun. Sebagain besar Member senam D'Ladies Kota Padang ingin menurunkan berat badan yang selama ini memberikan dampak yang negatif. Kelebihan berat badan selain merusak penampilan juga menimbulkan berbagai macam-macam penyakit yang mengganggu kesehatan mereka di antaranya, merasa sesak nafas meskipun hanya melakukan aktifitas ringan, badan terasa berat, sering kepanasan atau gerah, sering sakit pada bagian pinggang, 
panggul, paha, lutut, dan darah tinggi. Selain itu mudah mengalami kelelahan dalam berkatifitas.

Member senam aerobik dalam melakukan latihan juga tidak kontiniu, ada yang hanya datang seminggu sekali padahal sanggar senam memiliki jadwal latihan senam aerobik pada hari senin sampai dengan hari sabtu, pukul 08.00, 09.00, 17.00 dan 19.00. Selain bervariasinya jadwal latihan yang dapat dipilih oleh Member. Sanggar senam juga menyediakan alat-alat kebugaran seperti Dumbell, Yoga Ball, dan Stik Drum. Member senam melakukan senam aerobik diantaranya Body Language, Mixed Impact, dan Low Impact.

Observasi yang dilakukan ditemui bahwa instruktur kurang memahami apa yang harus dikuasai sebagai instruktur, seperti melakukan cek denyut nadi istirahat dan denyut nadi maksimal, kemudian instruktur juga tidak mengecek berat badan Member dan berat badan normal Member agar mengetahui perkembangan dari tujuan program yang diinginkan. Kemudian, jenis latihan belum sesuai dengan tujuan yang diinginkan, seperti program latihan yang belum mengacu pada latihan senam aerobik, serta kurangnya pemahaman Member terhadap pengaturan pola makan.

Selain itu, Member senam aerobik masih kurang motivasi dalam melakukan gerakan, seperti saat melakukan gerakan inti para Member cepat mengalami kelelahan, sehingga gerakan yang dilakukan tidak optimal. Peneliti melihat para Member dalam melakukan kegiatan tidak disiplin. Dilihat dari kehadiran Member sanggar senam D'Ladies Kota Padang, masih banyak Member yang datang tidak tepat waktu atau terlambat pada jadwal latihan senam aerobik. Motivasi latihan adalah salah satu yang paling penting yang harus dimiliki oleh member sanggar senam D'Ladies Kota Padang untuk melakukan latihan secara tekun dan penuh semangat. Motivasi latihan yang tinggi memungkinkan member berhasil menurunkan berat badan sesuai dengan yang diharapkan, sebaliknya apabila motivasi latihan rendah, dikhawatirkan akan berdampak terhadap hasil latihan yang dilakukan.
Hasil penelitian menunjukkan "(1) mixed impact aerobic exercise is more effective to reduce body fat than the low impact aerobic exercise, (2) there is an interaction between the type of exercise and exercise motivation (3) on high motivation group, the mixed impact training is more effective in reducing the percentage of body fat, while (4) on low motivation group, the low impact exercise is more effective in reducing the percentage of body fat (Saputri \& Sin, 2020)". Dapat disimpulkan bahwa (1) latihan aerobik impact campuran lebih efektif menurunkan lemak tubuh daripada latihan aerobik berdampak rendah, (2) terdapat interaksi antara jenis latihan dan motivasi latihan (3) pada kelompok motivasi tinggi, latihan campuran Latihan impak lebih efektif dalam menurunkan persentase lemak tubuh, sedangkan (4) pada kelompok motivasi rendah, latihan impact rendah lebih efektif menurunkan persentase lemak tubuh.

Dari beberapa uraian di atas, faktor metode latihan dan motivasi latihan merupakan faktor-faktor yang dianggap penting guna mempengaruhi penurunan lemak tubuh. Member sanggar senam D'Ladies Kota Padang akan berhasil dalam penurunan lemak tubuh yang maksimal apabila melakukan latihan fisik (olahraga). Apabila Member sanggar senam D'Ladies Kota padang melakukan latihan fisik (olahraga) dengan teratur dan berkesinambungan, maka anggota member sanggar senam D'Ladies dapat mengurangi lemak tubuh sehingga berat badan juga menurun. Aspek motivasi latihan juga sesuatu yang harus dimiliki setiap anggota member sanggar senam D'Ladies, rendahnya motivasi yang dimiliki akan menyebabkan anggota member sanggar senam D'Ladies Kota Padang tidak bisa latihan dengan penuh semangat, tekun, dan serius. Sebagai akibat, hal tersebut berdampak terhadap hasil latihan yang dicapai. Untuk mencapai hasil yang maksimal, maka setiap anggota Member sanggar senam D'Ladies Kota Padang harus memiliki motivasi latihan yang tinggi. 


\section{METODE}

\section{Metode dan Desain}

Jenis penelitian ini adalah ekperimen. "penelitian eksperimen merupakan penelitian yang menuntut peneliti memanipulasi dan mengendalikan satu atau lebih variabel bebas serta mengamati variabel terikat, untuk melihat perbedaan sesuai dengan manipulasi variabel bebas (Independent) tersebut atau penelitian yang melihat hubungan sebab akibat kepada dua atau lebih variabel dengan memberikan perlakuan lebih (Treatment) kepada kelompok eksperimen (Iskandar, 2008)".

Desain penelitian yang digunakan adalah rancangan Factorial 2 × 2, dimana masingmasing variabel bebas diklasifikasikan menjadi 2 (dua) bentuk metode latihan (A), yaitu metode latihan senam aerobik Mixed Impact (A1) dan metode latihan senam aerobik Low Impact (A2). Sedangkan variabel atribut/moderator diklasifikasikan dalam dua tingkatan motivasi latihan (B), yaitu motivasi latihan tinggi (B1) dan motivasi latihan rendah (B2).

Sebelum dilakukan pengelompokan sampel ke dalam rancangan faktorial 2 x 2 By Level, terlebih dahulu dilakukan tes terhadap variabel Atribut yaitu motivasi latihan. Hasil motivasi latihan di rangking dari skor urutan terbesar sampai urutan terkecil. Urutan data bagian atas dinamakan dengan kelompok motivasi latihan tinggi dan urutan data bagian bawah dinamakan dengan kelompok motivasi latihan rendah. Kemudian, masing-masing kelompok motivasi latihan tinggi dan motivasi latihan rendah dilakukan dengan cara Mached ke dalam sel, tujuannya agar data setiap sel rancangan tidak terdapat perbedaan secara statistik. Setelah semua data dikelompokkan berdasarkan tingkatan motivasi, kemudian diberi perlakuan senam aerobic Mixed Impact dan senam aerobic Low Impact. Untuk lebih jelasnya desain penelitian yang dilakukan dapat di lihat pada tabel 1 .
Tabel 1. Desain Factorial 2 x 2

\begin{tabular}{|c|c|c|}
\hline $\begin{array}{l}\text { Metode Latihan } \\
\text { (A) } \\
\text { Motivasi Latihan } \\
\text { (B) }\end{array}$ & $\begin{array}{c}\text { Mixed } \\
\text { Impact } \\
\left(\mathrm{A}_{1}\right)\end{array}$ & $\begin{array}{c}\text { Low Impact } \\
\left(\mathbf{A}_{2}\right)\end{array}$ \\
\hline Tinggi $\left(\mathrm{B}_{1}\right)$ & $\left(\mathrm{A}_{1} \mathrm{~B}_{1}\right)$ & $\left(\mathrm{A}_{2} \mathrm{~B}_{1}\right)$ \\
\hline Rendah $\left(B_{2}\right)$ & $\left(\mathrm{A}_{1} \mathrm{~B}_{2}\right)$ & $\left(\mathrm{A}_{2} \mathrm{~B}_{2}\right)$ \\
\hline Total & $\mathrm{A}_{1}$ & $\mathrm{~A}_{2}$ \\
\hline
\end{tabular}

Keterangan : Mixed Impact

A2 $=$ Kelompok metode latihan Low Impact

B1 $=$ Kelompok motivasi latihan tinggi

B2 = Kelompok motivasi latihan rendah

A1B1 = Kelompok metode latihan Mixed Impact motivasi latihan tinggi

A2B1 = Kelompok metode latihan Low Impact motivasi latihan tinggi

A1B2 = Kelompok metode latihan Mixed Impact motivasi latihan rendah

A2B2 $=$ Kelompok metode latihan Low Impact motivasi latihan rendah

\section{Partisipan}

Populasi dalam penelitian ini adalah semua Member sanggar senam D'Ladies Kota Padang yang aktif sebanyak 80 orang. Pengambilan sampel dalam penelitian ini menggunakan teknik Purposive Sampling, sehingga sampel berjumlah 40 orang dengan kriteria umur 20-30 tahun.

\section{Lokasi dan Waktu Penelitian}

Penelitian ini dilaksanakan di Universitas Negeri Medan pada Sabtu, 11 Januari 2020.

\section{Instrumen}

Data yang dikumpulkan ada dua macam yaitu: 1) data persentase lemak tubuh dan 2) angket motivasi latihan. Instrument untuk mengukur persentase lemak tubuh menggunakan Body Fat Analyzer dan motivasi latihan menggunakan angket model skala Likert. 


\section{Prosedur}

Agar proses pelaksanaan penelitian ini dapat berjalan lancar dan sesuai dengan apa yang diharapkan, maka perlu disusun atau dirancang beberapa perlakuan terhadap sampel. Rancangan tersebut meliputi :

1. Lama latihan secara keseluruhan dalam penelitian ini sebanyak 16 kali pertemuan

2. Frekuensi latihan dalam penelitian ini 3 kali dalam seminggu. Adapun pelaksanaan latihan pada hari hari senin,rabu, dan jumat, pukul 17.00 sampai selesai. Lama latihan dalam setiap pertemuan 45-60 menit.

\section{Analisis Data}

Setelah semua data terkumpul, kemudian data di analisis menggunakan Analysis Of Variance (ANOVA) dua jalur. Apabila hasil analisis varians menunjukkan adanya pengaruh utama (Main Effect) antara variabel bebas terhadap variabel terikat dan adanya interaksi (Simple Effect) variabel bebas terhadap variabel terikat maka dilanjutkan dengan uji Tuckey. Tujuan uji lanjut Tukey adalah untuk melihat kelompok mana yang memiliki perbedaan secara signifikan atau menentukan kelompok mana yang memiliki hasil yang lebih baik terhadap penurunan persentase lemak tubuh Member sanggar senam D'Ledies Kota Padang. Namun, sebelum dilakukan analisis pengolahan data maka terlebih dahulu dilakukan pengujian persyaratan analisis yaitu uji normalitas dan uji homogenitas data.

\section{HASIL}

Deskripsi data bertujuan untuk melihat secara umum gambaran karakteristik data penurunan persentase lemak tubuh yang menjadi subjek dalam penelitian ini. Hasil data penurunan persentase lemak tubuh terdiri dari empat kelompok perlakuan berdasarkan senam aerobik yaitu Mixed Impact dan Low Impact, serta motivasi latihan yaitu motivasi latihan tinggi dan motivasi latihan rendah.

Tabel 2. Deskripsi Data Pretest dan Posttest Kelompok Perlakukan

\begin{tabular}{|c|c|c|c|c|c|}
\hline \multirow[t]{2}{*}{ No } & \multirow{2}{*}{$\begin{array}{l}\text { Kelo } \\
\text { mpo } \\
\text { k }\end{array}$} & \multicolumn{2}{|l|}{ Rerata } & \multirow{2}{*}{$\begin{array}{l}\text { Selisih } \\
\text { Rata- } \\
\text { rata Pre- } \\
\text { Post }\end{array}$} & \multirow[b]{2}{*}{$\begin{array}{l}\text { Selisih } \\
\text { Rerata } \\
\text { Post-test } \\
\text { kel yang } \\
\text { dibanding } \\
\text { kan }\end{array}$} \\
\hline & & Pre-test & $\begin{array}{l}\text { Post- } \\
\text { test }\end{array}$ & & \\
\hline 1 & $\mathrm{~A}_{1}$ & 33,51 & 31,38 & 2,13 & \multirow[t]{2}{*}{1,03} \\
\hline 2 & $\mathrm{~A}_{2}$ & 34,22 & 32,41 & 1,81 & \\
\hline 3 & $\mathrm{~B}_{1}$ & 33,36 & 31,15 & 2,21 & \multirow[t]{2}{*}{1,50} \\
\hline 4 & $\mathrm{~B}_{2}$ & 34,37 & 32,65 & 1,72 & \\
\hline 5 & $\mathrm{~A}_{1} \mathrm{~B}_{1}$ & 32,75 & 29,83 & 2,92 & \multirow[t]{2}{*}{1,42} \\
\hline 6 & $\mathrm{~A}_{2} \mathrm{~B}_{1}$ & 33,96 & 32,46 & 1,50 & \\
\hline 7 & $\mathrm{~A}_{1} \mathrm{~B}_{2}$ & 34,26 & 32,93 & 1,33 & \multirow[t]{2}{*}{0,78} \\
\hline 8 & $\mathrm{~A}_{2} \mathrm{~B}_{2}$ & 34,47 & 32,36 & 2,11 & \\
\hline
\end{tabular}

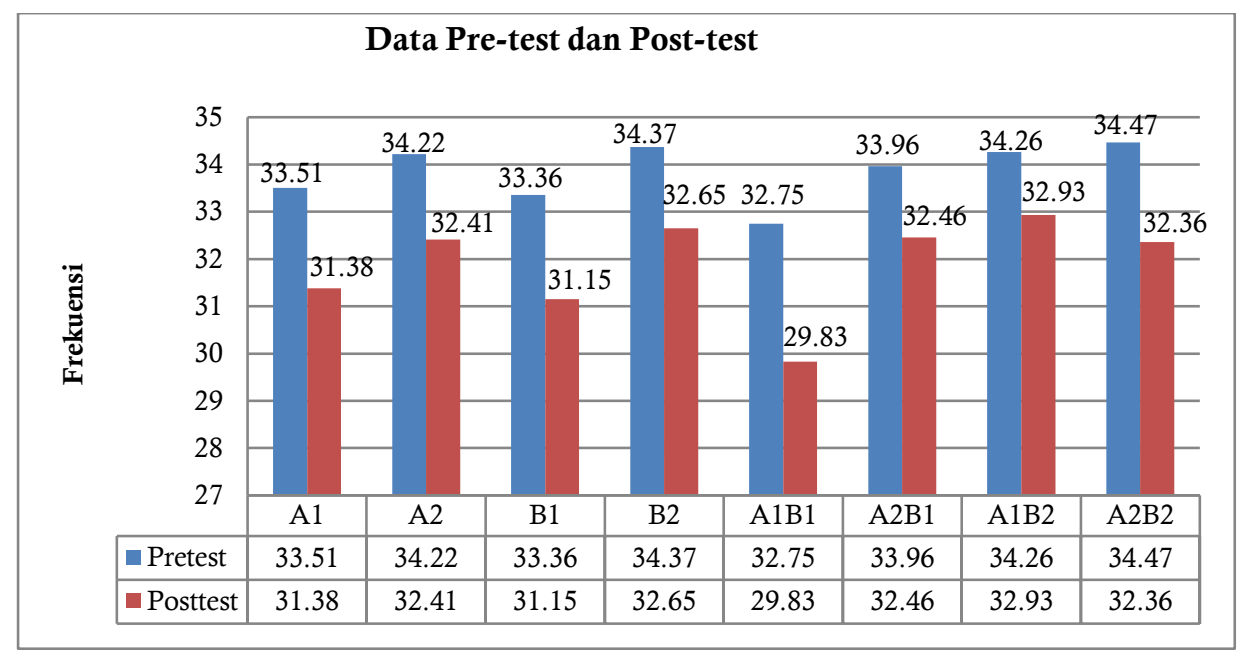

Gambar 1. Histogram Data Pretest dan Posttest 
Berdasarkan table 2, bahwa Pre-test kelompok $\mathrm{A} 1=33,51$ dan Post-test $=31,38$ dengan selisih rata-rata Pre-Post $=2,13$. Pre-test kelompok A2 $=34,22$ dan Post-test $=32,41$ dengan selisih rata-rata Pre-post $=1,81$. Selisih Post-test kelompok yang dibandingkan yaitu A1 dan $\mathrm{A} 2=1,03$. Pre-test kelompok B1 = 33,36 dan Post-test $=31,15$ dengan selisih rata-rata Pre-post $=2,21$. Pre-test kelompok B2 $=34,37$ dan Post-test $=32,65$ dengan selisih rata-rata Pre-post $=1,72$. Pretest kelompok A1B1 $=32,75$ dan Post-test $=29,83$ dengan selisih rata-rata Pre-post $=2,92$. Pretest kelompok A2B1 $=33,96$ dan Post-test $=32,46$ dengan selisih rata-rata Pre-post $=1,50$. Selisih Post-test kelompok yang dibandingkan yaitu A1B1 dan A2B1 = 1,42. Pretest kelompok A1B2 $=34,26$ dan Post-test $=$ 32,93 dengan selisih rata-rata Pre-post $=1,33$. Pretest kelompok A2B2 $=34,47$ dan Post-test $=$ 32,36 dengan selisih rata-rata Pre-Post $=2,11$. Selisih Post-test kelompok yang dibandingkan yaitu A1B2 dan A2B2 = 0,78.

Selanjutnya, pengujian hipotesis dilakukan dengan menggunakan Analysis Of Variance (ANOVA) By Level $2 \times 2$. Jika terdapat interaksi antara senam aerobik dengan motivasi latihan terhadap penurunan persentase lemak tubuh Member sanggar senam D'Ledies Kota Padang, maka dilanjutkan dengan Uji Tukey. Tujuan dari Analysis Of Variance (ANOVA) By Level 2 x 2 adalah untuk mengetahui bagaimanakah pengaruh variabel bebas terhadap hasil eksperimen dan untuk mengetahui pengaruh interaksi dari perlakuan yang diberikan. Untuk lebih jelasnya hasil pengujian hipotesis dapat dilihat pada tabel 3 .

Tabel 3. Rangkuman Hasil Analisys Of

Variance (ANOVA) $2 \times 2$

\begin{tabular}{|c|c|c|c|c|}
\hline Sumber Varians & $\mathrm{Db}$ & JK & $\mathrm{RK}=\mathrm{JK} / \mathrm{db}$ & $\begin{array}{c}\mathbf{F}_{\mathrm{h}}=\mathbf{R K} / \\
\text { RKD }\end{array}$ \\
\hline Antar Baris (b) & 1 & 22,50 & 22,50 & 11,77 \\
\hline Antar Kolom (k) & 1 & 10,61 & 10,61 & 5,55 \\
\hline Interaksi (bxk) & 1 & 25,60 & 25,60 & 13,39 \\
\hline $\begin{array}{l}\text { Dalam } \\
\text { Kelompok } \\
\text { (JKD) }\end{array}$ & 36 & 68,83 & 1,91 & \\
\hline Total Reduksi & 39 & 127,54 & & \\
\hline
\end{tabular}

Berdasarkan tabel 3 di atas, diperoleh antar baris atau Fhitung $(b)=11,77>$ Ftabel $=4,11$ maka Ho ditolak dan $\mathrm{Ha}$ diterima, sehingga dapat disimpulkan terdapat perbedaan yang signifikan antara senam aerobik Mixed Impact dengan senam aerobik Low Impact terhadap penurunan persentase lemak tubuh Member sanggar senam D'Ledies Kota Padang. Pada antar kolom atau Fhitung $(\mathrm{k})=5,55>$ Ftabel $=$ 4,11 maka Ho ditolak dan Ha diterima, sehingga dapat disimpulkan terdapat perbedaan yang signifikan antara motivasi latihan tinggi dengan motivasi latihan rendah terhadap penurunan persentase lemak tubuh Member sanggar senam D'Ledies Kota Padang. Selanjutnya, pada interaksi atau Fhitung (i) $=13,39>$ Ftabel $=$ 4,11 maka Ho ditolak dan Ha diterima, sehingga dapat disimpulkan terdapat interaksi yang signifikan antara senam aerobik dengan motivasi latihan terhadap penurunan persentase lemak tubuh Member sanggar senam D'Ledies Kota Padang.

Tabel 4. Rangkuman hasil ui lanjut analysis of variance (ANOVA)2x2 dengan uji Tukey

\begin{tabular}{ccccc}
\hline No & $\begin{array}{c}\text { Kelompok yang } \\
\text { dibandingkan }\end{array}$ & $\mathbf{Q}_{\text {hitung }}$ & $\begin{array}{c}\mathbf{Q}_{\text {tabe }} \\
\mathbf{1}\end{array}$ & Keterangan \\
\hline $\mathbf{1}$ & $\mathrm{A}_{1}$ dan $\mathrm{A}_{2}$ & 3,33 & 2,95 & Signifikan \\
\hline $\mathbf{2}$ & $\mathrm{A}_{1} \mathrm{~B}_{1}$ dan $\mathrm{A}_{2} \mathrm{~B}_{1}$ & 6,01 & 3,15 & Signifikan \\
\hline $\mathbf{3}$ & $\mathrm{A}_{1} \mathrm{~B}_{2}$ dan $\mathrm{A}_{2} \mathrm{~B}_{2}$ & 1,30 & 3,15 & $\begin{array}{c}\text { Tidak } \\
\text { Signifikan }\end{array}$ \\
\hline
\end{tabular}

Berdasarkan tabel 4 di atas, maka hipotesis hasil Analysis Of Variance (ANOVA) 2 × 2 dengan uji lanjut Uji Tukey dapat dianalisis sebagai berikut:

1. Perbedaan Pengaruh antara Senam Aerobik Mixed Impact dan Senam Aerobik Low Impact terhadap Penurunan Persentase Lemak Tubuh Member Sanggar Senam D'Ladies Kota Padang

Pengujian hipotesis pertama yaitu perbedaan keefektifan antara senam aerobik Mixed Impact dan senam aerobik Low Impact terhadap $\mathbf{F}_{t_{\text {penurunan }}}$ persentase lemak tubuh member 4, Isanggar senam D'Ladies Kota Padang. Hasil ,17engujian hipotesis diperoleh Qhitung $=3,33>$ , Atabel $=2,95$, sehingga dapat disimpulkan terdapat perbedaan keefektifan antara senam aerobik Mixed Impact dan senam aerobik Low Impact terhadap penurunan persentase lemak tubuh Member sanggar senam D'Ladies Kota Padang. Jika dilihat dari rata-rata yang dibandingkan, bahwa kelompok senam aerobik Mixed Impact lebih baik daripada kelompok 
senam aerobik Low Impact terhadap penurunan persentase lemak tubuh member sanggar senam D'Ladies Kota Padang (A1 = 31,38\% lemak dan $\mathrm{A} 2=32,41 \%$ lemak, dengan selisih rata-rata $1,03 \%)$.

2. Terdapat Interaksi antara Senam Aerobik dengan Motivasi Latihan terhadap Penurunan Persentase Lemak Tubuh Member Sanggar Senam D'Ladies Kota Padang

Pengujian hipotesis kedua yaitu interaksi antara senam aerobik dengan motivasi latihan terhadap penurunan persentase lemak tubuh Member sanggar senam D'Ladies Kota Padang. Hasil pengujian hipotesis diperoleh Fhitung $=13,39$ $>$ Ftabel $=4,11$, sehingga dapat disimpulkan bahwa terdapat interaksi antara senam aerobik dengan motivasi latihan terhadap penurunan persentase lemak tubuh Member sanggar senam D'Ladies Kota Padang. Artinya, kedua perlakuan senam aerobik Mixed impact dan senam aerobik Low Impact yang dilakukan secara tepat, terencana, berkesinambungan dan sesuai dengan prinsip-prinsip dasar latihan, maka akan terjadinya penurunan persentase lemak tubuh Member sanggar senam D'Ladies Kota Padang jika dilihat dari tingkat motivasi latihan tinggi dan rendah. Untuk lebih jelasnya dapat dilihat pada gambar 2 .

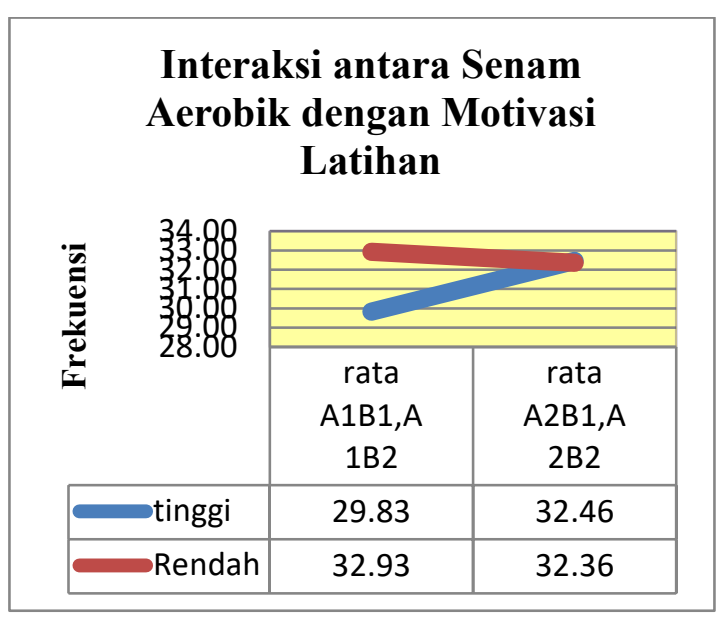

Gambar 2. Interaksi antara Senam Aerobik dengan Motivasi Latihan

3. Perbedaan Pengaruh antara Senam Aerobik Mixed Impact dan Senam Aerobik Low
Impact dilihat dari Motivasi Latihan Tinggi terhadap Penurunan Persentase Lemak Tubuh Member Sanggar Senam D'Ladies Kota Padang

Pengujian hipotesis ketiga yaitu perbedaan keefektifan antara kelompok yang diberikan perlakuan senam aerobik Mixed Impact dan senam aerobik Low Impact dilihat dari motivasi latihan tinggi terhadap penurunan persentase lemak tubuh Member sanggar senam D'Ladies Kota Padang. Hasil pengujian hipotesis diperoleh Qhitung $=6,01>$ Qtabel $=3,15$, sehingga dapat disimpulkan bahwa terdapat perbedaan pengaruh antara senam aerobik Mixed Impact dan senam aerobik Low Impact dilihat dari motivasi latihan tinggi terhadap penurunan persentase lemak tubuh member sanggar senam D'Ladies Kota Padang. Jika dilihat dari rata-rata yang dibandingkan, bahwa kelompok yang diberikan perlakuan senam aerobik Mixed Impact dengan motivasi latihan tinggi lebih baik daripada kelompok yang diberikan perlakuan senam aerobik Low Impact dengan motivasi latihan tinggi (A1B1 $=29,83 \%$ lemak dan A2B1 $=32,46 \%$ lemak, dengan selisih rata-rata $1,42 \%)$.

4. Perbedaan Pengaruh antara Senam Aerobik Mixed Impact dan Senam Aerobik Low Impact dilihat dari Motivasi Latihan Rendah terhadap Penurunan Persentase Lemak Tubuh Member Sanggar Senam D'Ladies Kota Padang

Pengujian hipotesis keempat yaitu perbedaan keefektifan antara kelompok yang diberikan perlakuan senam aerobik Mixed Impact dan senam aerobik Low Impact dilihat dari motivasi latihan rendah terhadap penurunan persentase lemak tubuh Member sanggar senam D'Ladies Kota Padang. hasil pengujian hipotesis diperoleh Qhitung $=1,30<$ Qtabel $=3,15$, sehingga dapat disimpulkan bahwa tidak terdapat perbedaan pengaruh antara senam aerobik Mixed Impact dan senam aerobik Low Impact dilihat dari motivasi latihan rendah terhadap penurunan persentase lemak tubuh Member sanggar senam D'Ladies Kota Padang. Jika dilihat dari rata-rata yang dibandingkan, bahwa tidak terdapat perbedaan rata-rata yang 
signifikan antara kelompok perlakuan senam aerobik Mixed Impact dan senam aerobik Low Impact dengan motivasi latihan rendah $(\mathrm{A} 1 \mathrm{~B} 2=$ $32,93 \%$ lemak dan A2B2 $=32,36 \%$ lemak dengan selisih rata-rata $0,78 \%$ ).

\section{PEMBAHASAN}

Sebelum melakukan program latihan peneliti memberikan arahan kepada Member sanggar senam D'Ladies untuk mengatur pola makan dalam membatasi kalori yang masuk per harinya agar pada saat latihan Member bisa melaksanakan gerakan yang sesuai dengan apa yang diberikan instruktur, sehingga tidak adanya kesulitan bergerak karena terlalu banyak pemasukan kalori. Semakin banyak kalori yang masuk, maka para Member akan kesulitan bergerak, malas untuk bergerak, serta pembakaran lemak pun lebih lambat. Oleh sebab itu, sebaiknya Member memperhatikan pola makan yang benar selama program ini dilaksanakan, sehingga tujuan program ini tercapai dalam penurunan persentase lemak tubuh. Setelah melakukan latihan, para Member harus menjaga pola makan agar tercapainya penurunan persentase lemak tubuh, dengan diberikannya arahan pola makan yang benar, peneliti mengarahkan agar dalam pemasukan kalori tidak lebih dari 2.000 kalori dalam satu hari untuk program penurunan berat badan.

Senam aerobik adalah latihan yang dilakukan untuk membakar lemak sambil memperbaiki kekencangan otot yang dipimpin oleh instruktur berpengalaman secara bersamasama dengan diiringi musik yang sesuai dengan irama/gerakan untuk anggota tubuh yang bergerak. (Jonni, 2011) mengemukakan, melakukan senam aerobik secara teratur, terprogram akan mendapat manfaat sebagai berikut : kerja jantung lebih efesien dan menjadi terlatih sehingga jantung tidak cepat lelah, pembuluh darah akan lebih besar sehingga darah akan semakin lancar mengalir ke seluruh tubuh, mencegah terjadinya pengumpalan darah, paruparu akan bertambah kapasitas pernapasannya, jantung akan memompakan darah lebih banyak dari berdenyut lebih lambat, berkurangnya risiko gangguan pada jantung, tekanan darah yang sebelumnya tinggi akan menurun secara teratur, terjadinya penurunan kadar lemak yang baik sehingga bermanfaat di dalam tubuh, terulangulang persendian dan otot-otot menjadi lebih kuat, kemampuan tubuh atau kebugaran jasmani akan semakin meningkat.

Senam aerobik Low Impact merupakan gerakan-gerakan yang banyak melangkah dan satu kaki tetap dilantai, tidak melompat. Namun bukan berarti intensitas gerakannya rendah. Jenis ini baik diterapkan untuk pemula dan usia lanjut, sering juga dikenal dengan latihan yang aman dari resiko cidera. Low impact ini juga dianjurkan bagi mereka yang baru mulai melakukan latihan senam aerobik. Senam aerobik Low Impact merupakan gerakan senam yang dilakukan dengan irama Low (rendah) yaitu bentuk gerakannya lebih lambat, dengan gerakan dasar jalan, dan tidak ada gerakan melompat sama sekali. Uraian di atas dimaknai bahwa latihan senam aerobik Low Impact membutuhkan daya tahan dan kekuatan. Diutamakan keterampilan gerak dengan merangkai sesuai dengan irama musik, dengan tempo lambat dan cepat, sehingga tercapai keharmonisan gerakan. Sedangkan senam aerobik Mixed Impact merupakan latihan penggabungan dari dua jenis senam aerobik Low Impact dan High Impact. Dimana pada Low Impact aerobik tidak memberikan beban yang terlalu besar pada persendian-persendian. Bila kita mengangkat lutut harus betul-betul terangkat, jika tidak dapat menggunakan momentum lompatan. Jadi dapat mengencangkan kaki lebih cepat, otot-otot paha bagian depan biasanya mendapat beban yang paling banyak. Berikut kelebihan dan kekurangan dari masing-masing senam aerobic.

\begin{tabular}{ll}
\hline Kelebihan & Kekurangan \\
\hline Mixed Impact: & Mixed Impact: \\
- Variasi gerakan & $-\begin{array}{l}\text { Memiliki resiko } \\
\text { lebih banyak }\end{array}$ \\
- $\begin{array}{l}\text { Lebih } \\
\text { bersemangat }\end{array}$ \\
- Intenstitas sedang \\
- Menggunakan \\
$\begin{array}{l}\text { energi lebih } \\
\text { banyak }\end{array}$ \\
\hline
\end{tabular}




\begin{tabular}{ll}
\hline Low Impact: & Low Impact: \\
- Resiko cidera & - Kurang optimal \\
rendah & - Intensitas rendah \\
- Santai & \\
- Baik untuk usia & \\
lanjut & \\
\hline
\end{tabular}

Berdasarkan uraian tersebut, bahwa dari kedua perlakuan senam aerobik yaitu senam aerobik Mixed Impact dan senam aerobik Low Impact memiliki bentuk gerakan yang berbeda dalam pelaksanaannya, sehingga terdapat perbedaan pengaruh terhadap penurunan persentase lemak tubuh Member sanggar senam D'Ladies Kota Padang secara keseluruhan. Kelebihan senam aerobik Mixed Impact antara lain, variasi gerakan yang banyak, intensitas sedang, dan menggunakan energi yang lebih banyak. Sedangkan kelebihan senam aerobik Low Impact antara lain, resiko cedera rendah, santai dan dianjurkan untuk usia lanjut. Dengan kata lain, senam aerobik Mixed Impact lebih baik dari pada senam aerobik Low Impact terhadap penurunan persentase lemak tubuh Member sanggar senam D'Ladies Kota Padang.

Hasil penelitian (Partadinata et al., 2017) menunjukkan bahwa, "latihan senam aerobik low impact memberikan pengaruh yang signifikan terhadap penurunan massa lemak tubuh (skin fold). Latihan senam aerobik high impact memberikan pengaruh yang signifikan terhadap penurunan massa lemak tubuh (skin fold) serta latihan senam aerobik Low Impact lebih memberikan hasil yang sangat signifikan terhadap penurunan massa lemak tubuh dibandingkan dengan latihan senam aerobik High impact". Hasil penelitian (Putri et al., n.d.) juga menunjukkan bahwa, "adanya efek dari latihan senam aerobik mix impact terhadap penurunan kadar lemak tubuh anggota sanggar senam Rai Sawahlunto".

Selanjutnya, motivasi diartikan sebagai pendorong atau penggerak dalam diri manusia yang diarahkan dalam tujuan tertentu. Seseorang dalam menampilkan perilakunya dan melakukan suatu pekerjaan, pada prinsipnya didasarkan pada suatu keinginan, kebutuhan, kemauan, dan gerak hatinya yang diarahkan pada suatu tujuan. Keinginan atau kemauan untuk berperilaku dan bekerja inilah yang disebut dengan motivasi. Hamalik dalam (Sutrisno, 2017) mengemukakan "ada dua prinsip yang digunakan untuk meninjau motivasi. (1) Motivasi dipandang sebagai suatu proses, (2) Motivasi merupakan suatu perubahan energi dalam diri seseorang yang ditandai dengan timbulnya perasaan dan reaksi mencapai tujuan". Motivasi latihan adalah sumber penggerak dan pendorong tingkah laku manusia untuk melakukan kegiatan olahraga guna mencapai tujuan tertentu. Hasil latihan (aktivitas) yang maksimal akan terwujud secara baik apabila motivasi latihan ada dan timbul dari diri seseorang. (Suparmin, 2003) mengemukakan bahwa "ciri-ciri motivasi adalah (1) Berusaha lebih keras, (2) Mempunyai prakarsa dalam tugas, (3) Ingin segera mengetahui hasi dari usahanya, (4) Lebih realistis".

Hasil penelitian (Saputri \& Sin, 2020) menunjukkan bahwa (1) mixed impact aerobic exercise is more effective to reduce body fat than the low impact aerobic exercise, (2) there is an interaction between the type of exercise and exercise motivation (3) on high motivation group, the mixed impact training is more effective in reducing the percentage of body fat, while (4) on low motivation group, the low impact exercise is more effective in reducing the percentage of body fat. Dapat disimpulkan bahwa (1) latihan aerobik Impact campuran lebih efektif menurunkan lemak tubuh daripada latihan aerobik berdampak rendah, (2) terdapat interaksi antara jenis latihan dan motivasi latihan (3) pada kelompok motivasi tinggi, latihan campuran Impact lebih efektif dalam menurunkan persentase lemak tubuh, sedangkan (4) pada kelompok motivasi rendah, latihan Impact rendah lebih efektif menurunkan persentase lemak tubuh. Hasil penelitian (Sitepu et al., 2020) juga menunjukkan bahwa, terdapat pengaruh yang signifikan antara latihan senam aerobik mix impact dengan latihan senam kebugaran jasmani 2012 terhadap penurunan persentase lemak tubuh. Penelitian ini juga 
menyimpulkan adanya interaksi antara latihan dan motivasi berolahraga.

Berdasarkan uraian tersebut, dapat disimpulkan bahwa penurunan persentase lemak tubuh Member sanggar senam D'Ladies Kota Padang dapat dilakukan dengan senam aerobik Mixed Impact dan senam aerobik Low Impact. Selanjutnya, dalam pemberian senam aerobik disesuaikan dengan motivasi latihan Member yaitu motivasi latihan tinggi dan rendah

\section{KESIMPULAN}

Berdasarkan pada temuan penelitian dan pembahasan hasil penelitian, maka dapat disimpulkan bahwa terdapat perbedaan pengaruh antara senam aerobik Mixed Impact dan senam aerobik Low Impact terhadap penurunan persentase lemak tubuh Member sanggar senam D'Ladies Kota Padang, yang mana senam aerobik Mixed Impact lebih baik dari pada senam aerobik Low Impact terhadap penurunan persentase lemak tubuh Member sanggar senam D'Ladies Kota Padang. Terdapat interaksi antara senam aerobik dengan motivasi latihan terhadap penurunan persentase lemak tubuh Member sanggar senam D'Ladies Kota Padang. Member sanggar senam D'Ladies Kota Padang yang memiliki motivasi latihan tinggi hendaknya diberikan perlakuan senam aerobik Mixed Impact jika ingin terjadinya penurunan persentase lemak tubuh, dan bagi Member yang memiliki motivasi latihan rendah, dapat diberikan kedua senam aerobik tersebut jika ingin terjadinya penurunan persentase lemak tubuh, tetapi cenderung akan lebih baik jika diberikan senam aerobik Low Impact, hal ini disebakan perbedaan jumlah rata-rata dari hasil penelitian yang telah dilakukan.

\section{UCAPAN TERIMAKASIH}

Terimakasih kami ucapkan kepada semua pihak yang membantu dalam penelitian ini, utamanya Fakults Ilmu Keolahragaan Universitas Negeri Padang yang telah memfasilitasi dan memberi izin serta semua stakeholder yang terlibat di dalamnya.

\section{REFERENSI}

Almatsier, S. (2004). Prinsip Dasar Ilmu Gizi. Jakarta: PT. Gramedia Pustaka Utama.

Asriah, D., \& Prasetyo, H. J. (2018). Pengaruh Senam Aerobik Mix Impact terhadap Penurunan Berat Badan pada Ibu Ibu Obesitas di Desa Pengkol Kecamatan Karanggede Kabupaten Boyolali Tahun 2018 Dini. Jurnal Kepelatihan Olahraga SMART SPORT, 12(1), 1-7.

Dewi, R., \& Muhammad Sazeli Rifki. (2020). Pengaruh.Senam.Aerobik.terhadap.tingkat .Kebugaran.Jasmani Siswa Rahayu. JURNAL STAMINA, 3(6), 398-416.

Hembing, W. (2001). 15 Menit Menuju Sehat dengan Ayunan Tangan. Jakarta: PT. Gramedia Pustaka Umum.

Hiklová, P., \& Gába, A. (2019). Effect of Aerobics on Weight and Fat Mass Loss in Adult Women: Systematic Review and Meta-Analysis. Acta Gymnica, 49(3), 144152.

https://doi.org/(https://creativecommons .org/licenses/by/4.0/

Iskandar. (2008). Metodologi Penelitian Pendidikan Sosial (Kuantitatif dan Kualitatif). Jakarta: Gaung Persada Press (GP Press).

Jonni. (2011). Senam Aerobik. Padang: Fakultas Ilmu Keolahragaan Universitas Negeri Padang.

Kurniadi. (2006). Prinsip Dasar Ilmu Gizi. Jakarta: PT. Gramedia Pustaka Umum.

Moehji, S. (2017). Dasar-Dasar Illmu Gizi. Jakarta: Pustaka Kemang.

Nawawi, U. (2014). The Effect of Low Impact and Mixed Impact Aerobic Exercise on Percentage of Body Fat. Asian Social Science, 10(5), 163-167. https://doi.org/10.5539/ass.v10n5p163 
Partadinata, W. A., Gandari, G. P., \& Mudian, D. (2017). Pengaruh Latihan Senam Aerobik Low Impact dan High Impact terhadap Penurunan Massa Lemak Tubuh (Skin Fold). BIORMATIKA Jurnal Ilmiah FKIP Universitas Subang, 4(2).

Purwanto. (2011). Dampak Senam Aerobik terhadap Daya Tahan Tubuh dan Penyakit. Jurnal Media Ilmu Keolahragaan Indonesia, $\quad 1(1), \quad 1-9$. http://journal.unnes.ac.id

Putri, E. P., Syahrastani, \& Tohidin, D. (n.d.). Pengaruh Senam Aerobik Mix Impact terhadap Penurunan Kadar Lemak Tubuh. Sport Science: Jurnal Sain Olahraga Dan Pendidikan Jasmani, 71-82. http://sportscience.ppj.unp.ac.id/index.p $\mathrm{hp} / \mathrm{jss} /$ index

Saputri, H., \& Sin, T. H. (2020). The Effect of Low Impact Aerobic Exercise, Mixed Impact and Training Motivation on Weight Loss Percentage of Army Wives at Batalyon Infantry 133 YS Padang. Proceedings of the 1st Progress in Social Science, Humanities and Education Research Symposium (PSSHERS 2019) The, 464(Psshers 2019), 839-847.

Sitepu, M. S. Z., Tangkudung, J., \& Puspitorini, W. (2020). Pengaruh Latihan Senam Aerobik dan Motivasi Berolahraga terhadap Penurunan Persentase Lemak Tubuh. Jurnal Penjaskesrek, 7(1), 45-59.

Sumanto, A. (2009). Tetap Langsing dan Sehat dengan Terapi Diet. Jakarta: PT. Agro Media Pustaka.

Suparmin. (2003). Motivasi dan Ertos Kerja. Jakarta: Biro Kepegawaian Depag RI.

Sutrisno, E. (2017). Manajemen Sumber Daya Manusia. Jakarta: Kharisma Putra Utama. 